\title{
Proceeding
}

Supplementary Issue: Autumn Conferences of Sports Science. Costa Blanca Sports Science Events, 18-19 December 2020. Alicante, Spain.

\section{Effect of progressive prone plank exercise program on diastasis of rectus abdominis muscle in postpartum women: A randomized controlled trial}

\author{
EMAN AWAD ${ }^{1}$, ALI MOBARK², AHMED A. ZIDAN ${ }^{3}$, HAMADA A. HAMADA $^{4}$, TAMER SHOUSHA ${ }^{5,6}$ \\ ${ }^{1}$ Physical Therapy Department for Woman and Child Health, Faculty of Physical Therapy, Beni-Suef University, Beni- \\ Suef, Egypt \\ ${ }^{2}$ Department of Gynaecology and Obstetrics, Faculty of Medicine, Beni-Suef University, Beni-Suef, Egypt \\ ${ }^{3}$ Department of Radiology, Faculty of Medicine, Beni-Suef University, Beni-Suef, Egypt \\ ${ }^{4}$ Department of Biomechanics, Faculty of Physical Therapy, Cairo University, Cairo, Egypt \\ ${ }^{5}$ Department of Physical Therapy, CHS, University of Sharjah, United Arab Emirates \\ ${ }^{6}$ Department of Physical Therapy for Musculoskeletal Disorders and its Surgery, Faculty of Physical Therapy, Cairo \\ University, Egypt
}

\begin{abstract}
Diastasis of Rectus Abdominis (DRA) muscle is a concerning health issue that commonly affects female within pregnancy and postpartum time, persistent lower back pain and pelvic instability are common consequences to DRA. Thus, this study was conducted to examine the effect of progressive prone plank exercises on narrowing the inter-Rectus distance (IRD) in postpartum women diagnosed with (DRA). A prospective, randomized, single-blind, controlled trial was conducted at the Faculty of Physical Therapy Clinic of Beni-Suef University. Fifty postpartum women presented with (DRA) of at least 2 finger widths assigned into 2 equal groups (A\&B). A Toshiba Xario100, 8-12 MHz ultrasonography was used to accurately measure IRD before and after 8 weeks of the exercise program. Group (A), received progressive prone plank exercise program and advice relevant to DRA as well as wore abdominal binder, while group (B) continued their ordinary lifestyle after receiving advice and wearing abdominal binder as group (A).The study results revealed a statistical significant decrease within each group and between groups in $\operatorname{IRD}(p<.05)$ above and below the umbilicus both at rest and during Rectus Abdominis (RA) contraction, with a significantly narrower IRD in favoured of participants of group $(A)(p<.05)$. To sum it up, progressive prone plank exercise program is very effective in decreasing IRD in postpartum women presented with DRA.

Keywords: Diastasis rectus abdominis; Inter-rectus distance; Rectus Abdominis; Ultrasonography; Measurement; Prone plank exercise.

Cite this article as:

Awad, E., Mobark, A., Zidan, A.A., Hamada, H.A., \& Shousha, T. (2021). Effect of progressive prone plank exercise program on diastasis of rectus abdominis muscle in postpartum women: A randomized controlled trial. Journal of Human Sport and Exercise, 16(2proc), S395-S403. doi:https://doi.org/10.14198/jhse.2021.16.Proc2.24

Corresponding author. Department of Biomechanics, Faculty of Physical Therapy, Cairo University, Cairo, Egypt.

E-mail: m.mana.qeshm@gmail.com

Abstract submitted to: Autumn Conferences of Sports Science. Costa Blanca Sports Science Events, 18-19 December 2020. Alicante, Spain.

JOURNAL OF HUMAN SPORT \& EXERCISE ISSN 1988-5202

(c) Faculty of Education. University of Alicante

doi:10.14198/jhse.2021.16.Proc2.24
\end{abstract}




\section{INTRODUCTION}

DRA is an abnormal widening of the gap between the two bellies of the RA muscle resulting from prolonged transverse stresses on the linea alba (Benjmin et al., 2014; Bates-Maves, \& O'Sullivan, 2017). It is a concerning health issue affecting females during pregnancy as well as postpartum period especially multiparous (Maurice Nahabedian, 2018). The 'inter-rectus distance' [IRD] is expressed as the far among the medial borders of the two [RA] bellies (Mota et al., 2012). USI is considered the most accurate and reliable method for measuring DRA in clinical practice (Van de Water \& Benjamin, 2016). Distance between the two parts of the right abdominal muscle of more than 2 to $2.7 \mathrm{~cm}$ is called rectal diastasis, which can affect abdominal actions like breathing, urination, and labour, and may alter the body position. Involve the pelvic lumbar region. Considering the importance of exercise therapy in the treatment of rectal diastasis, the present study aimed to investigate the effect of strengthening exercises of the oblique muscles on the distance between the right abdominal muscles and abdominal muscle thickness in female with rectal diastasis.

DRA prevalence is reported to be between $30 \%$ to $70 \%$ during pregnancy and up to $60 \%$ in postpartum period; it is a relatively common problem that negatively impact women's health (Mota et al., 2015; Coldron et al., 2008; Sperstad et al., 2016; Sheykh, \& Emadian, 2020). Certain abdominal exercises such as abdominal crunches and sit-ups can exacerbate (DRA) symptoms due to their action in pushing (RA) bellies away. In addition, certain activities of daily living such as bending while getting up from bed or carrying heavy objects can worsen the condition (Benjamin and Van De Water, 2016).

Pregnancy DRA results from softening and expansion of the linea alba which occurs due to release of relaxing, progesterone and oestrogen hormones. Also, mechanical stresses placed on the abdominal wall to accommodate the growing foetus and displacement of the abdominal organs play an important role in developing DRA during pregnancy. Lower back pain and pelvic instability are common consequences to DRA during pregnancy because, the integrity, mechanical control and functional strength of the abdominal muscles markedly reduce during pregnancy (Stephenson \& O'Connor, 2000; Parker et al., 2009; Keshwani et al, 2017).

Reducing IRD by prescribing therapeutic exercises and abdominal binders are relevant methods used in conservative rehabilitation of DRA cases (Keeler et al., 2012). Traditional abdominal exercises, postural and back care education as well as training on the appropriate mobility and lifting techniques, are all examples of non-surgical interventions used on regular basis with postnatal women with DRA (Opala-Berdzik \& Dabrowski, 2009; Gitta et al., 2016; Benjmin et al., 2014; Keler et al., 2012; Gitta et al., 2016).

The most used exercises are strengthening programs for rectus abdominis muscle [RA] or transversus abdominis muscle $[\mathrm{TrA}]$.Trunk stability is also regained and maintained by strengthening deep multifidus, TrA, pelvic floor, and diaphragm or the deep core stabilizing muscles which form a muscular cylinder, that supports the spine and the pelvis (Khandale \& Hande, 2016; Akuthota et al., 2008; Feldwieser et al., 2012).

More importantly, the isometric plank exercises are considered safe due to their role in minimizing spine loads while providing longer duration of muscle tension in comparison with dynamic abdominal exercises (Imai et al., 2010; Lehman et al., 2005; Lee \& McGill, 2015; Ekstrom et al., 2007).

Therefore, the main objective of the current research was to evaluate the influence of progressive prone plank exercises on decreasing the IRD in postpartum female presented with DRA. 


\section{METHODOLOGY}

The research is designed as a randomized controlled trial that compared 2 groups of participants. Group A (experimental group) included participants who joined a progressive prone plank exercise program in addition to wearing a belly band and receiving advice to help with their DRA (Keeler et al., 2012). While group (B) involved control participants who wore the same belly band and received advice as group (A) participant. The research is performed between March 2019 and Dec 2019. The investigation linked to human utilize has been interconnected by whole the relevant national regularities and policies (BSU P.T 09 on February 12, 2019).

\section{Participants}

A total of 60 women were assessed for eligibility with the inclusion criteria of the study. Of these, 10 women did not meet the study criteria or refused to participate and thus were excluded. Finally, 50 women participated in the study (Figure 1). All of them selected from the obstetric outpatient clinic of Beni-Suef University Hospital, Beni-Suef, Egypt. Their ages ranged from 23-35 years and their body mass index [BMI] did not exceed $29 \mathrm{~kg} / \mathrm{m}^{2}$. All participants were postpartum women at their three to six months after normal vaginal delivery with the presence of DRA (Van de Water \& Benjamin, 2016).

Women were excluded from the study, if they were diagnosed with heart diseases, respiratory diseases causing excessive coughing or sneezing, chronic physical or mental illness, had a deformed or obscured linea alba or umbilicus; had rheumatologic or connective tissue disease; had any medical condition that would prohibit active abdominal muscle contraction; or had DRA measured to less than two finger widths as well as those who underwent any pelvic or abdominal surgery; or failed to complete an informed consent form.

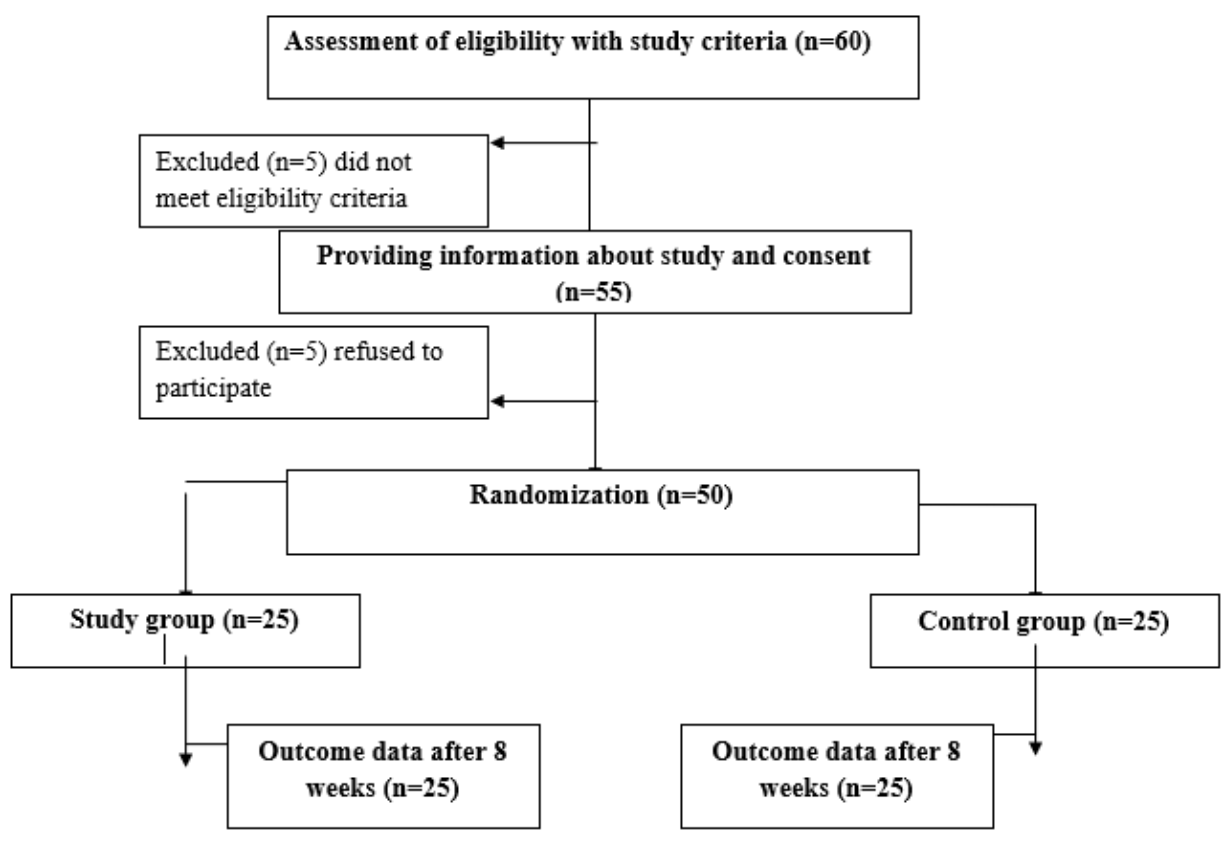

Figure 1. Randomization, participants flow chart.

\section{Randomization}

Anonymity of participants' data was assured by coding of all data. Assigning participants to groups was conducted by a blinded and an independent research assistant, who randomly allocated participants into 2 groups equal. 


\section{Intervention procedure}

Women fulfilling the inclusion criteria were informed about the study. All exercise sessions were held by the same physiotherapist at the Faculty of Physical Therapy Outpatient Clinic, Beni-Suef University. Participants of both groups (A \& B) used abdominal binder specialized for DRA as the belly band during any weight bearing activities throughout the study period. Also, they were advised on healthy diet, ideal posture for lifting objects; for getting out the bed as well as getting out of bath. Next, group A participants performed a progressive prone plank exercise. The exercise program characteristics included a frequency of a minimum 3 times per week, intensity set at moderately hard perceived exertion for a total of 8 weeks. During the one month of the exercises, the exercise session started with light walking for 5 minutes followed by corrected exercise to overcome the effect of poor pregnancy posture. Then, participants performed first step of prone plank exercises which was a stable prone plank with attention to maintain a neutral position. Second step of prone plank exercises involved performing the unilateral stable prone plank which was the same as the stable prone plank but with the dominant leg in a fully extended position away from the support surface. Third step included, prone bridge on a Swiss Ball with a diameter of $65 \mathrm{~cm}$ similar to the stable prone plank exercise, but with the forearms resting on a Swiss Ball. On the second 4 weeks of the exercise program, participants repeated the same exercises except for the progressive prone plank exercise steps, which were performed for 3 sets of 20 repetitions while holding each contraction 1 minute, followed by 2 minutes of relaxation. Exercise group participants attended the exercise program three times per week, they were instructed to regularly perform the previous exercises at home throughout the study period.

\section{Outcome measure}

Main outcome: Change in IRD measured in mm by USI at rest and during contraction of RA $4.5 \mathrm{~cm}$ above and below the umbilicus for all participants before and after the exercise program.

\section{Ultrasound imaging}

All assessments were performed by the third researcher at the radiology department of Beni-Suef University Hospital. USI was done by a two-dimensional ultrasound diagnostic scanner with a linear probe [Toshiba Xario100, 8-12 MHz linear transducer]. USI was conducted before and after 8 weeks of the intervention procedure for all participants. By using the umbilicus as the point of reference, measurement locations were $4.5 \mathrm{~cm}$ above the umbilical midpoint and $4.5 \mathrm{~cm}$ below the umbilical midpoint (Parker et al., 2009; Mota et al., 2013).

The locations were initially marked on the skin by using a soluble marker to standardize the position of the transducer while participant was lying in supine position (Mota et al., 2013; Teyhen et al., 2008).

Ultrasound's integrated measurement tool was used to measure IRD between the related medial borders of the two RA bellies (Chiarello et al., 2012; Mota et al. 2012). All participants were assessed for the presence and size of DRA as well as their ability to contract RA correctly prior to the USI.

\section{Data analysis}

Test size estimation was performed before the investigation utilizing G*POWER statistical programming. This effect size calculated from pilot study on10 participants (5 in each group) (Figure 2).

The normal $Q-Q$ plot was used to confirm normal distribution of data. Homogeneity of variances $(p>.05)$ was observed by Levene's test. While inferential statistics involved the calculation of differences within and between groups. 


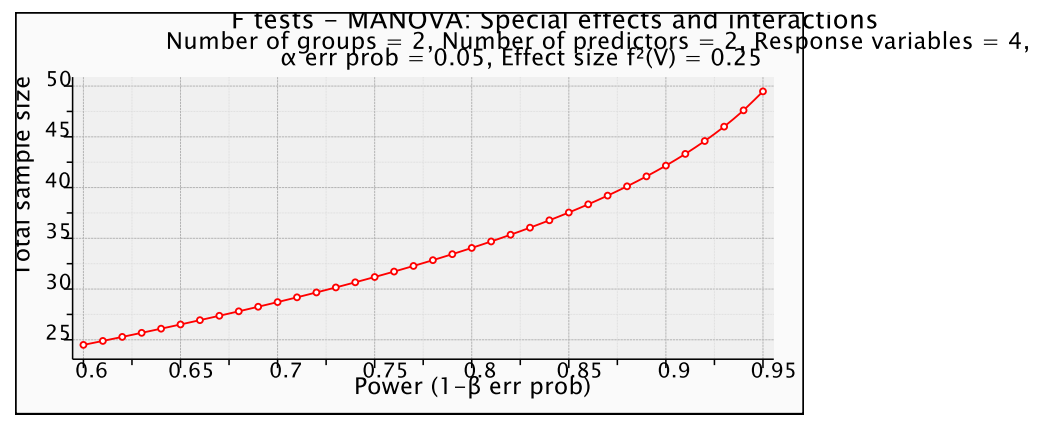

Figure 2. Plot of sample size calculation.

\section{RESULTS}

Fifty postpartum women presented with DRA were randomized and assigned into 2 equal groups. Data extracted from 25 women in each group was analysed after completion of the intervention procedure. There were no statistically significant differences $(p>.05)$ between participants in both groups concerning age and BMI (Table 1).

Table 1. Physical characteristics of participants in each group.

\begin{tabular}{lccc}
\hline & Group A & Group B & \multirow{2}{*}{$p$-value } \\
\cline { 2 - 3 } & Mean \pm SD & Mean \pm SD & .217 \\
\hline Age(Years) & $27.04 \pm 3.52$ & $28.24 \pm 3.24$ & .723 \\
BMI $\left(\mathrm{Kg} / \mathrm{m}^{2}\right)$ & $27.48 \pm 0.22$ & $27.36 \pm 0.24$ & \\
\hline & \multicolumn{2}{c}{ Note: ${ }^{*} p$-value <.05: significant. }
\end{tabular}

Table 2. Descriptive and inferential statistics for inter-recti distance $(\mathrm{mm})$ at rest and during contraction of Rectus Abdominis muscle before and after treatment for both groups.

\begin{tabular}{|c|c|c|c|c|}
\hline Inter-recti distance & & Group $(A)(n=25)$ & Group (B) $(n=25)$ & $p$-value ${ }^{*}$ \\
\hline \multirow{3}{*}{$\begin{array}{l}4.5 \mathrm{~cm} \text { above umbilicus at } \\
\text { rest }(\mathrm{mm})\end{array}$} & Pre-treatment & $29.69 \pm 1.61$ & $29.69 \pm 1.61$ & $1.00^{\mathrm{NS}}$ \\
\hline & Post-treatment & $20.84 \pm 1.97$ & $26.16 \pm 2.10$ & $.001^{\mathrm{s}}$ \\
\hline & p value ${ }^{* \star}$ & $.001^{\mathrm{S}}$ & $.001^{\mathrm{S}}$ & \\
\hline \multirow{3}{*}{$\begin{array}{l}4.5 \mathrm{~cm} \text { below umbilicus at } \\
\text { rest }(\mathrm{mm})\end{array}$} & Pre-treatment & $23.48 \pm 1.73$ & $23.62 \pm 1.71$ & $.78^{\mathrm{NS}}$ \\
\hline & Post-treatment & $16.88 \pm 2.58$ & $20.90 \pm 1.90$ & $.001^{\mathrm{s}}$ \\
\hline & $p$ value ${ }^{* *}$ & $.001^{\mathrm{s}}$ & $.001^{\mathrm{s}}$ & \\
\hline \multirow{3}{*}{$\begin{array}{l}4.5 \mathrm{~cm} \text { above umbilicus at } \\
\text { RA contraction }(\mathrm{mm})\end{array}$} & Pre-treatment & $32.58 \pm 1.77$ & $32.58 \pm 1.77$ & $1.00^{\mathrm{NS}}$ \\
\hline & Post-treatment & $23.44 \pm 2.30$ & $27.62 \pm 1.86$ & $.001^{\mathrm{s}}$ \\
\hline & $p$ value $e^{\star *}$ & $.001^{\mathrm{s}}$ & $.001^{\mathrm{s}}$ & \\
\hline \multirow{3}{*}{$\begin{array}{l}4.5 \mathrm{~cm} \text { below umbilicus at } \\
\text { RA contraction (mm) }\end{array}$} & Pre-treatment & $27.81 \pm 1.74$ & $27.62 \pm 2.13$ & $.73^{\mathrm{NS}}$ \\
\hline & Post-treatment & $20.80 \pm 1.73$ & $24.001 \pm 0.72$ & $.001^{\mathrm{s}}$ \\
\hline & $p$ value ${ }^{* *}$ & $.001^{\mathrm{s}}$ & $.001^{\mathrm{s}}$ & \\
\hline
\end{tabular}

Note: * Inter-group comparison; ** intra-group comparison of the results pre- and post-treatment, RA: Rectus Abdominis. 
Statistical investigations applying mixed design MANOVA indicated that there are positive direct relationship within subject impact $(F=150.505, p=.0001)$ and time of treatment impact $\left(F=68.56, p=.0001^{*}\right)$; While $F=11.303, p=.0001^{*}$. Within groups, the multiple pairwise comparison tests revealed a statistically significant decrease within each group in $\operatorname{IRD}(p<.05)$ above and below the umbilicus both at rest and during RA contraction after completing the study.

Regarding between groups, multiple pairwise comparisons revealed that there was significantly narrower IRD $(p<.05)$ in favoured of group (A) compared to group (B) after completing the intervention procedure. While there was no statistically significant difference between groups in IRD before the study $(p>.05)$ (Table 2).

\section{DISCUSSION}

In the present study, there were 2 statistically significant findings revealed concerning the postpartum women assigned to perform progressive prone plank exercises and their controls. First, the IRD measurements revealed a decrease within each group with a narrower gap in favoured of participants of group A after completion of the study. Second, between groups comparison revealed a considerable decrease in IRD again in favoured of group $[A]$ participants after the intervention procedure.

These results are in agreement with those of Chiarlo and Litos (Chiarello et al., 2005; Litos, 2014), who found that therapeutic exercise had a great effect on reducing DRA by two centimetres and increasing abdominal strength and endurance as a consequence to follow a regimen of stabilization exercises and using abdominal bracing. The results of the present study can be explained in terms of the adaptive changes occur in muscles in response to therapeutic exercises. Therapeutic exercises recruit more motor units within muscle fibres, activate both fast twitch [FT] and slow twitch[ST] fibres of the skeletal muscles, as the high content of FT fibres improves muscle strength. Additionally, they profusely affect the metabolic demand needed to produce a given muscle force which leads to increase in muscular power and endurance (Snijders et al., 2012). Also, the current results are in line with those studies who advised female patients presented with DRA to avoid exercises which cause the bulging of the abdominal wall such as abdominal sit-ups and crunches. The isometric plank exercises have been widely used as core stability exercises. Reducing back pain caused by DRA can be achieved by adding core exercise which proved effective in closing and treating DRA (Chiarello et al., 2005; Walton et al., 2016; Rathi, 2013).

Furthermore, another study found that unilateral support version of plank exercise resulted in high stages of muscle action in comparison to the bilateral version of the exercise. The same study supported using devices that challenge the stability of the plank exercise by making the supporting ground unstable, to efficiently train the core muscles and improve and restore balance and proprioception (El-Mekawy et al., 2013; Sancho et al., 2015; Ekstrom et al., 2007). On the other hand , the results of this study are not in line with the results of two recent studies which investigated the immediate effect of the 'drawing in' exercise on IRD compared with a traditional crunch exercise, where the IRD was increased with the 'drawing in' exercise (Mota et al.,2015 and Sancho et al.,2015).

The results of this study provide therapists with valuable information to improve decision making in designing exercise programs to treat DRA in postpartum women.

\section{Limitations}

The small sample size recruited in the present study could be its major limitation despite its design (a randomized controlled clinical trial). According to the basis of sample size calculation, with the power of the 
study $1-B=80 \%$ to evaluate the impact size of $d=0.5$ with a significance level less than $.05,50$ participants must be related to groups $A$ and $B$. It is not possible to evaluate the specific impact of each type of prone plank exercises on DRA in postpartum women.

\section{CONCLUSION}

Eventually, it could be founded that progressive prone plank exercise program is effective in decreasing IRD in postpartum women presented with DRA. Many scientific and professional reports stress the importance of adding core stability exercises early in rehabilitation of postpartum women with DRA to enhance quality of life and prevent complications arising from this condition.

\section{REFERENCES}

Akuthota, V., Ferreiro, A., Moore, T., \& Fredericson, M. (2008). Core Stability Exercise Principles. Curr Sports Med Rep, 7(1), :39-44. https://doi.org/10.1097/01.CSMR.0000308663.13278.69

Bates-Maves, J. K., \& O'Sullivan, D. (2017). Trauma-informed risk assessment in correctional settings. International Journal of Criminology and Sociology, 6, 93-102. https://doi.org/10.6000/19294409.2017.06.10

Benjamin, D.R., van de Water, A.T., \& Peiris, C.L. (2014). Effects of exercise on diastasis of the rectus abdominis muscle in the antenatal and postnatal periods: a systematic review. Physiotherapy, 100, 1-8. https://doi.org/10.1016/i.physio.2013.08.005

Chiarello, C.M., Falzone, L.A., McCaslin, K.E., Patel, M.N., \& Ulery, K.R. (2005). The Effects of an exercise program on diastasis recti abdominis in pregnant women. J Women's Health PhysTher, 29, 11-6. https://doi.org/10.1097/01274882-200529010-00003

Chiarello, C.M., Zellers, J.A., \& Sage-King, F.M. (2012). Predic ᄀtors of inter-recti distance in cadavers. J Womens Health PhysTher, 36, 125-130. https://doi.org/10.1097/JWH.0b013e318276f60e

Coldron, Y., Stokes, M.J., Newham, D.J., \& Cook, K. (2008). Postpartum characteristics of rectus abdominis on ultrasound imaging. Man Ther, 13, 112-21. https://doi.org/10.1016/..math.2006.10.001

Ekstrom, R.A., Donatelli, R.A., \& Carp, K.C. (2007). Electromyographic analysis of core trunk, hip, and thigh muscles during 9 rehabilitation exercises. J Orthop Sports PhysTher, 37, 754-62. https://doi.org/10.2519/jospt.2007.2471

El-Mekawy, H., Eldeeb, A., El- Lythy, M., \& El-Begawy, A. (2013). Effect of Abdominal Exercises versus Abdominal Supporting Belt on Post-Partum Abdominal Efficiency and Rectus Separation. Int J Med Health Sci, 7(1), 75-9.

Feldwieser, F.M., Sheeran, L., Meana-Esteban, A., et al. (2012). Electromyographic analysis of trunkmuscle activity during stable, unstable and unilateral bridging exercises in healthy individuals. Eur Spine J, 21(Suppl 2), S171-86. https://doi.org/10.1007/s00586-012-2254-7

Gitta, S., Magyar, Z., Tardi, P., et al. (2016). How to Treat Diastasis Recti Abdominis with Physical

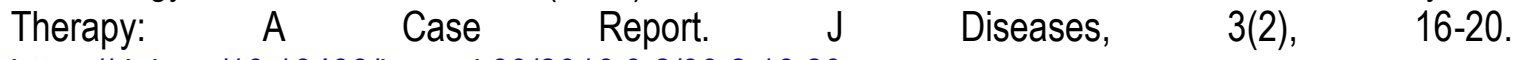
https://doi.org/10.18488/journal.99/2016.3.2/99.2.16.20

Imai, A., Kaneoka, K., Okubo, Y., et al. (2010). Trunk muscle activity during lumbar stabilization exercises on both a stable and unstable surface. J Orthop Sports PhysTher, 40, 369-75. https://doi.org/10.2519/jospt.2010.3211

Keeler, J., Albrecht, M., Eberhardt, L., Horn, L., Donnelly, C., \& Lowe, D. (2012). Diastasis recti abdominis: a survey of women's health specialists for current physical therapy clinical practice for postpartum women. J Women's Health PhysTher, 36, 131-42. https://doi.org/10.1097/JWH.0b013e318276f35f 
Keshwani, N., Mathur, S., \& McLean, L. (2017). Relationship between Inter-rectus Distance and Symptom Severity in Women with Diastasis Recti in the Early Postpartum Period. Physical therapy. Dec 4. https://doi.org/10.1093/pti/pzx117

Khandale, S.R., \& Hande, D. (2016). Effects of abdominal exercises on reduction of diastasis recti in postnatal women. Int J Health Sci Res, 6(6), 182-191.

Lee B.C.Y., McGill, S.M. (2015). Effect of long-term isometric training on core/torso stiffness. J Strength Cond Res, 29, 1515-26. https://doi.org/10.1519/JSC.0000000000000740

Lehman, G.J., Hoda, W., Oliver, S. (2005). Trunk muscle activity during bridging exercises on and off a Swiss ball. ChiroprOsteopat, 13, 14. https://doi.org/10.1186/1746-1340-13-14

Litos, K. (2014). Progressive Therapeutic Exercise Program for Successful Treatment of a Postpartum Woman with a Severe Diastasis Recti Abdominis. J Womens Health PhysTherap, 38(2), 58-73. https://doi.org/10.1097/JWH.0000000000000013

Maurice Nahabedian, D.C. (2018). Brooks. "Rectus abdominis diastasis". UpToDate. Retrieved 201801-26. Topic 100494 Version 5.0.

Mota, P., Pascoal, A.G., Carita, A.I., \& Bø, K. (2015). Prevalence and risk factors of diastasis recti abdominis from late pregnancy to 6 months postpartum, and relationship with lumbo-pelvic pain. Man Ther, 20, 200-5. https://doi.org/10.1016/j.math.2014.09.002

Mota, P., Pascoal, A.G., Carita, A.I., \& Bo, K. (2015). The immediate effects on inter-rectus distance of abdominal crunch and drawing-in exercises during pregnancy and the postpartum period. $J$ Orthopaed Sports Phys Ther, 45, 781-8. https://doi.org/10.2519/jospt.2015.5459

Mota, P., Pascoal, A.G., Sancho, F., \& Bo, K. (2012). Test-retest and intraraterreliability of 2-dimensional ultrasound measurements of distance between rectus abdominis in women. J Orthopaed Sports Phys Ther, 42, 940-6. https://doi.org/10.2519/jospt.2012.4115

Mota, P., Pascoal, A.G., Sancho, F., Carita, A.I., \& Bø, K. (2013). Reliability of the inter-rectus distance measured by palpation. Comparison of palpation and ultrasound measurements. Man Ther, 18, 2948. https://doi.org/10.1016/i.math.2012.10.013

Opala-Berdzik, A., \& Dabrowski, S. (2009). Physiotherapy in diastasis of the rectus muscles of abdomen in women during pregnancy and postpartum. Fizjoterapia, 17(4), 67-70. https://doi.org/10.2478/v10109-010-0039-2

Parker, M., Millar, L., \& Dugan, S. (2009). Diastasis rectus abdominis and lumbo-pelvic pain and dysfunction - Are they related? JWomens' Health PhysTherap, 33(2), 15-22. https://doi.org/10.1097/01274882-200933020-00003

Rathi, M. (2013). Effect of pelvic floor muscle strengthening exercises in chronic low back pain. IJPOT, 7(1), 121-5.

Sancho, M.F., Pascoal, A.G., Mota, P., \& Bø, K. (2015). Abdominal exercises affect inter-rectus distance in postpartum women: a two-dimensional ultra-sound study. Physiotherapy, 101, 286-91. https://doi.org/10.1016/j.physio.2015.04.004

Sheykh, S. F. M., \& Emadian, S. O. (2020). Investigating the Relationship between the Conflict Resolution Skills among Couples on the Level of Marital Conflict and Their Mental Health (Case Study: Centers of Psychological and Counseling Services of Qaemshahr City). Journal of Social Sciences and Humanities Research, 8(1).

Snijders, T., Verdijk, L.B., Beelen, M., McKay, B.R., Parise, G., Kadi, F., \& Van Loon, L.J. (2012). A single bout of exercise activates skeletal muscle satellite cells during subsequent overnight recovery. ExpPhysiol, 97(6), 762-73. https://doi.org/10.1113/expphysiol.2011.063313

Sperstad, J.B., Tennfjord, M.K., Hilde, G., Ellström-Engh, M., \& Bø, K. (2016). Dias-tasis recti abdominis during pregnancy and 12 months after childbirth:prevalence, risk factors and report of lumbopelvic pain. Br J SportsMed, 50, 1092-6. https://doi.org/10.1136/bjsports-2016-096065 
Stephenson, R.G., \& O'connor, L.J. (2000). Obstetric and gynecologic care in physical therapy, 2nd Ed. New York: Slack incorporated press.

Teyhen, D.S., Rieger, J.L., Westrick, R.B., Miller, A.C., Molloy, J.M., \& Childs, J.D. (2008). Changes in deep abdominal muscle thickness during common trunk-strengthening exercises using ultrasound imaging. J Orthop Sports PhysTher, 38, 596-605. https://doi.org/10.2519/jospt.2008.2897

Van de Water, A.T., \& Benjamin, D.R. (2016). Measurement methods to assess diastasis of the rectus abdominis muscle (DRAM): a systematic review of their measurement properties and meta-analytic reliability generalization. Manual therapy, 1(21), 41-53. https://doi.org/10.1016/j.math.2015.09.013

Walton, L., Costa, A., LaVanture, D., Mcllrath, S., \& Stebbins, B. (2016). The effects of a 6 week dynamic core stability plank exercise program compared to a traditional supine core stability strengthening program on diastasis recti abdominis closure, pain, oswestry disability index (ODI)and pelvic floor disability index scores (PFDI). PhyTherRehab, 3(1), 3. https://doi.org/10.7243/2055-2386-3-3 